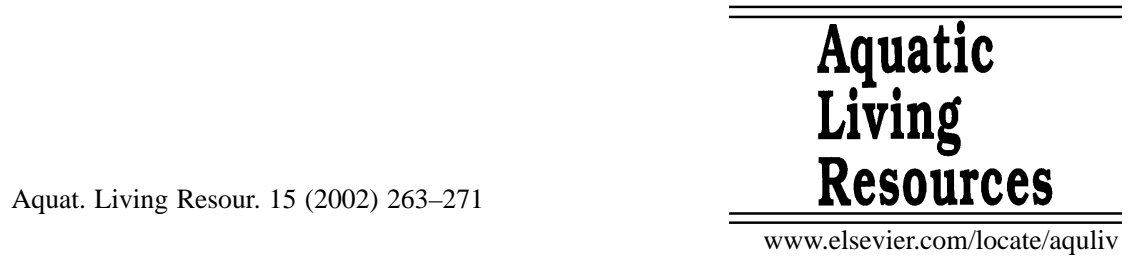

Original article

\title{
Point, alpha and beta diversity of carnivorous fish along a depth gradient
}

\author{
Pascal Lorance $^{\mathrm{a}, *}$, Sami Souissi ${ }^{\mathrm{b}}$, Franz Uiblein ${ }^{\mathrm{c}}$ \\ a IFREMER, BP 70, 29280 Plouzané, France \\ ${ }^{\mathrm{b}}$ Ecosystem Complexity Research Group, Station Marine de Wimereux, USTL CNRS-UMR 8013 ELICO, 28, avenue Foch, BP 80, 62930 Wimereux, \\ France \\ ${ }^{\mathrm{c}}$ Institute of Zoology, University of Salzburg, Hellbrunnerstr. 34, A-5020 Salzburg, Austria
}

Received 28 June 2002; accepted 25 September 2002

\begin{abstract}
The catch from bottom longline stations sampled from a series of research cruises around Lanzarote and Fuerteventura (Canary Islands, NE Atlantic) was analysed in terms of fish distribution, density and diversity. The distribution of the number of species and individuals caught per station appeared to fit well the Poisson and Exponential distribution function, respectively. In particular, the parameter of the Poisson's distribution appeared to provide an index of the point (at station scale) diversity, and its confidence interval, allowing for statistical comparisons. The relationships between point diversity, the alpha diversity (in the depth strata) and the beta diversity (along the depth gradient) were investigated. Around the islands, the density and the point diversity of the predator fish declined with depth down to about $800 \mathrm{~m}$ and then increased in the deeper stratum. The alpha diversity was the lowest in the deeper stratum but the taxonomic distinctness was similar to that of shallower strata. The beta diversity showed some faunal breaks along the depth gradient. The carnivorous fish fauna can be understood as comprised of three major assemblages: shelf, upper slope and mid-slope that are different both in terms of species composition and point, alpha and beta diversities. The relevance of this simple method for ecological studies of fish assemblage in the context of non-trawlable grounds is discussed, in particular for the slope and other areas of established or developing deep-water fisheries. (C) 2002 Ifremer/CNRS/Inra/IRD/Cemagref/Éditions scientifiques et médicales Elsevier SAS. All rights reserved.
\end{abstract}

\section{Résumé}

Diversité des poissons carnivores à l'échelle locale de l'échantillon (diversité alpha) et le long d'un gradient de profondeur (diversité beta). Les captures à la palangre de fond de stations échantillonnées, lors d'une série de campagnes de recherche autour de Lanzarote et Fuerteventura (îles Canaries, Atlantique Nord-Est) ont été analysées en termes de distribution, densité et diversité des poissons. Il est apparu que la distribution du nombre d'espèces et d'individus par station s'ajustait bien à la fonction de distribution de Poisson, et à la fonction exponentielle, respectivement. En particulier, les paramètres de la distribution de Poisson fournissent un indice de la diversité locale (à l'échelle de la station) et son intervalle de confiance, ce qui autorise des comparaisons statistiques. Les relations entre la diversité locale, la diversité alpha (échelle de la strate bathymétrique) et la diversité beta (le long du gradient de profondeur) ont été explorées. Autour des îles étudiées, la densité et la diversité locale des poissons prédateurs diminuent avec la profondeur jusqu'à $800 \mathrm{~m}$ environ, puis augmentent au-delà. La diversité alpha est plus faible dans la strate la plus profonde mais un indice de diversité basé sur la distance taxonomique est similaire dans toutes les strates. La diversité beta fait apparaître des ruptures faunistiques le long du gradient de profondeur. La faune de poissons carnivores peut se décrire à travers 3 assemblages principaux : plateau, pente supérieure et pente moyenne qui sont différents à la fois en termes de composition spécifique et de diversité locale, alpha et beta. Ainsi, cette approche simple permet d'étudier l'écologie des assemblages de poissons sur les fonds non chalutables. Sa pertinence est discutée pour le talus continental et les autres zones, où des pêcheries profondes sont bien établies ou en cours de développement. @ 2002 Ifremer/CNRS/Inra/IRD/Cemagref/Éditions scientifiques et médicales Elsevier SAS. Tous droits réservés.

Keywords: Longline; Demersal fishes; Diversity; Density; Probability distributions; Canary islands

\footnotetext{
* Corresponding author.

E-mail address: pascal.lorance@ifremer.fr (P. Lorance).
} 


\section{Introduction}

Most ecological studies of fish assemblages addressing the depth and geographical distributions of species, their density, diversity, and the effect of exploitation have been based on trawl sampling. Such studies have been much less advanced in the context of non-trawlable grounds, such as the waters surrounding oceanic islands, seamounts and ridges. In these areas, fisheries exploitation and scientific investigation rely on fixed gears. Examples of such fisheries include both longstanding fisheries, such as the longline fishery for the black scabbard fish (Aphanopus carbo) in Madeira (Leite, 1988; Martins and Ferreira, 1995) and more recent ones (Iglesias and Paz, 1995; Piñeiro et al., 2001). Estimating and following up over time the fish diversity in these areas should be of help to assess the sustainability of current and developing fisheries.

Although they are recognized as the only gear that can be used on some rocky or sloping bottoms, longlines are not often used for stock assessment (Hovgard and Riget, 1992). The reasons for this are their species and size selectivity (Løkkeborg and Bjordal, 1992), their fixed nature (Hovgard and Riget, 1992) and the role of the fish behaviour in the species composition of the catch and catch rate (Engås and Løkkeborg, 1994; Løkkeborg, 1994). Their use for ecological purposes is limited too.

The present paper is an attempt to widen the usefulness of longlining data by considering them as a sampling gear for top predators and scavengers. The data from a series of bottom-longlining cruises around Lanzarote and Fuerteventura, Canary Islands (Uiblein et al., 1996, 1998) are analysed to address the following specific and more general questions: (i) What are the distribution patterns of the diversity and density of predatory and scavenger fish species around the Canary Islands? (ii) How can data from longline surveys be analysed in terms of density and diversity to allow for comparison between different areas or ecosystems? (iii) Can longline data be used for investigating possible changes in fish assemblages caused by fishery exploitation?

To answer these questions, the fish diversity, in the studied area, was compared over different scales using some methods and indices reviewed by Gray (2000). Here, the point diversity (a single sample) was defined as the diversity for one longline station and the alpha diversity (samples within a habitat) was the diversity within a depth strata. The distributions of the number of species (point diversity) and the number of individuals per station were fitted to the Poisson and Exponential probability distributions, respectively. The alpha diversity was assessed using Hill's and taxonomic distinctness indices (Hill, 1973; Warwick and Clarke, 1995). The beta diversity was studied in terms of species richness. Two aspects of the beta diversity (see Gray (2000) for a review of definitions and usages) were studied: the participation of the difference between stations to the alpha diversity and the turnover diversity from one depth stratum to the next. The advantages of these distributions and indices were discussed and briefly compared with alternative approaches, such as indicator species.

\section{Materials and methods}

\subsection{Data}

Two hundred stations were distributed along 21 transects perpendicular to the coastline and an additional 23 stations deeper than $800 \mathrm{~m}$ were concentrated to the SE of $\mathrm{Fu}$ erteventura off Gran Tarajal (Fig. 1). Each station was sampled with a 300 hook longline, details of the sampling methods are in Rico et al. (1999). Five depth strata, S1 to S5, were defined using a simple process (Lorance et al., 2001). Their depth ranges were: $22-224 \mathrm{~m} ; 278-437 \mathrm{~m}$; 495-594 m; 656-777 m and 816-1208 m. A correspondence analysis (CA) showed a depth effect in S1, which was then subdivided into two substrata $\mathrm{S} 1 \mathrm{a}$ and $\mathrm{S} 1 \mathrm{~b}$, which were shallower and deeper than $100 \mathrm{~m}$, respectively. The CA did not detect any geographical patterns in fish distribution around the Islands (Lorance et al., 2001). All sampling stations and fish species caught were processed (there were some zero catches) including a small number of pelagic species (Uiblein et al., 1996).

\subsection{Point diversity and fish density}

The catch of one species by a single longline haul can be considered as a rare event, so the total number of species

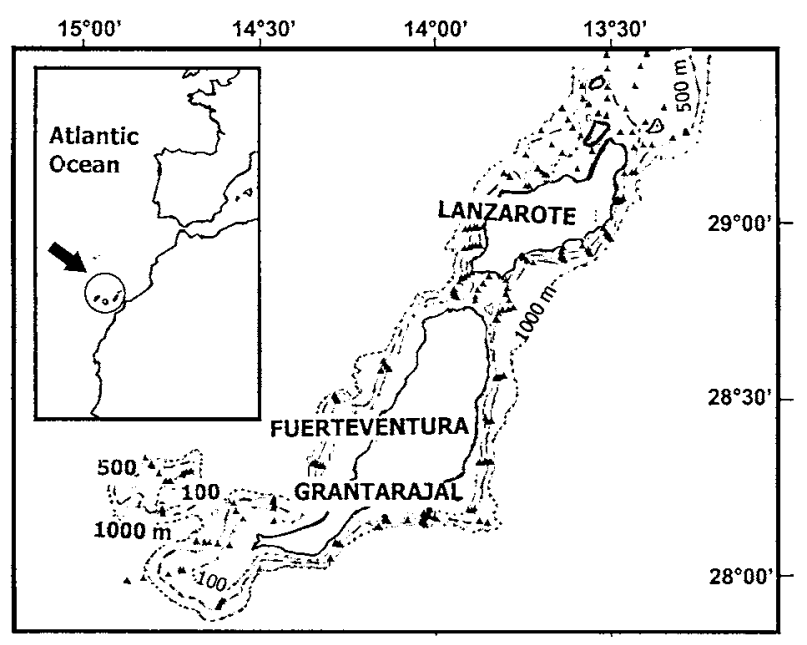

Fig. 1. Distribution map of the sampling stations (21 transects and additional 23 stations deeper than $800 \mathrm{~m}$ ) around Lanzarote and Fuerteventura (Canary Islands). 
caught should follow the Poisson distribution. The probability of obtaining $k$ species in a station is expressed as:

$$
P(k)=\mathrm{e}^{-\lambda} \frac{\lambda^{k}}{k !} \quad k=0,1,2, \ldots, \infty
$$

Where $\lambda$ is the mean of the distribution, which is equal to the variance of the distribution.

Although the number of individuals caught per sample is also a discrete variable, the shape of its distribution was closer to the Exponential distribution. For $x>0$, the exponential probability density function is given by:

$$
f(x)=\theta \mathrm{e}^{-\theta x}
$$

Where $\theta$ is a positive parameter. The expectation of $x$ is $\mu=E[x]=1 / \theta$ and its variance is $1 / \theta^{2}$.

The Poisson distribution was fitted to the frequency distribution of the number of species in each stratum and in the whole area. The cumulative distribution of the number of individuals caught in a stratum was fitted to the Exponential cumulative distribution function.

The curve fitting toolbox of MATLAB software was used to estimate the parameters using a non-linear optimisation algorithm.

\subsection{Alpha diversity}

Considering that depth strata are habitats, the diversity per stratum is an alpha diversity in the sense of Whittaker (1960). This diversity was estimated from some of Hill's indices (Hill, 1973).

Hill's indices can be expressed from one single equation:

$$
N_{a}=\left(\sum_{i=1}^{n} p_{i}^{a}\right)^{1 /(1-a)}
$$

Where $a$ is the order of the diversity index, $p_{i}$ is the relative abundance of species $i$ in the sample, $n$ is the total number of species present in the sample.

With the notation from this author, the species richness is denoted $N_{0} ; N_{1}$ is the exponentiation of the Shannon index; $N_{2}$ the reciprocal of the Simpson index; $N_{\infty}$ is the reciprocal of the relative frequency of the commonest species.

Evenness was also estimated according to Hill (1973), any number of the following form is an evenness index:

$$
E_{a, a-1}(S)=N_{a}(S) / N_{a-1}(S)
$$

Where $E_{a, a-1}(S)$ are evenness indices and $N_{a}(\mathrm{~S})$ diversity numbers for stratum $\mathrm{S}$.

Any ratio of $N_{a}$ numbers is an evenness index. $E_{2,1}$ is more suitable than the usual $E_{1,0}$ because it is less dependent on sample size (Hill, 1973).
In addition to Hill's indices, the $\Delta$ and $\Delta^{*}$ taxonomic distinctness were computed (Warwick and Clarke, 1995):

$$
\begin{gathered}
\Delta=\frac{\sum_{j=1}^{s} \sum_{i=1}^{j-1} w_{i j} N_{i} N_{j}}{\sum_{j=1}^{S} \sum_{i=1}^{j-1} N_{i} N_{j}+\sum_{i=1}^{S} N_{i}\left(N_{i}-1\right) / 2} \\
\Delta^{*}=\frac{\sum_{j=1}^{s} \sum_{i=1}^{j-1} w_{i j} N_{i} N_{j}}{\sum_{j=1}^{S} \sum_{i=1}^{j-1} N_{i} N_{j}}
\end{gathered}
$$

Where $w_{i j}$ is a weight factor given for the taxonomic distinctness between species.

Following Hall and Greenstreet (1998), for species in the same genus $w=1$; for species in different genera but the same family $w=2$; for species in different families, but the same order $w=3$; for species in different orders $w=4$.

\subsection{Beta diversity}

Two facets of the beta diversity were studied. The participation of the difference between points to the alpha diversity was estimated as (Gray, 2000):

$$
\beta_{\mathrm{S}}=N_{0 \mathrm{~S}} / \lambda
$$

Where $\beta_{\mathrm{S}}$ is the beta diversity within stratum $\mathrm{S} ; N_{\mathrm{OS}}$ is the species richness in stratum $S ; \lambda$ is the average point species richness in stratum $\mathrm{S}$.

$\beta_{\mathrm{S}}$ is clearly sensitive to the sample size, as when more stations are sampled in one stratum, $N_{\mathrm{OS}}$ tends to increase while $\lambda$ remains stable.

The change in alpha diversity along the depth gradient (the turnover diversity), was assessed as:

$$
\beta_{\mathrm{D}}=\frac{G+L}{N_{0 \mathrm{~S}}+N_{0 \mathrm{~T}}}
$$

Where $\beta_{\mathrm{D}}$ is the beta diversity along the gradient from stratum $\mathrm{S}$ to stratum $\mathrm{T} ; G$ is the number of species gained when passing from stratum $\mathrm{S}$ to stratum $\mathrm{T} ; L$ is the number of species lost when passing from stratum $\mathrm{S}$ to stratum $\mathrm{T}$; $N_{\text {OS }}$ and $N_{\text {OT }}$ are the species richness is strata $\mathrm{S}$ and $\mathrm{T}$.

\subsection{Indicator species}

The specificity and fidelity of each species $s$ compared to each cluster of stations (corresponding here to a depth stratum) can be measured by the values $S P_{j, s}$ and $F I_{j, s}$, respectively:

$$
\begin{gathered}
S P_{j, s}=N I_{j, s} / N I_{+j} \\
F I_{j, s}=N S_{j, s} / N S_{j+}
\end{gathered}
$$


Table 1

Number of stations, species and individuals per stratum; averages, bounds of the 95\% confidence intervals (CI) and determination coefficient of the Poisson's $(\lambda)$ and Exponential $(\mu)$ distributions (see text)

\begin{tabular}{|c|c|c|c|c|c|c|c|c|c|}
\hline \multirow[t]{2}{*}{ Stratum } & \multirow[t]{2}{*}{ Stations } & \multirow[t]{2}{*}{ Species } & \multirow[t]{2}{*}{ Individuals } & \multicolumn{3}{|c|}{ Poisson's distribution } & \multicolumn{3}{|c|}{ Exponential distribution } \\
\hline & & & & $\lambda$ & CI & $R^{2}$ & $\mu$ & CI & $R^{2}$ \\
\hline All & 223 & 73 & 1885 & 2.43 & $1.89-2.97$ & 0.52 & 8.16 & $7.73-8.59$ & 0.99 \\
\hline $\mathrm{S} 1$ & 94 & 53 & 1236 & 4.26 & $4.01-4.51$ & 0.99 & 13.00 & $12.2-13.70$ & 0.98 \\
\hline S1a & 44 & 38 & 622 & 3.89 & $3.26-4.53$ & 0.80 & 14.30 & $13.3-15.30$ & 0.97 \\
\hline $\mathrm{S} 1 \mathrm{~b}$ & 50 & 35 & 614 & 4.86 & $4.21-5.51$ & 0.69 & 11.80 & $11.2-12.40$ & 0.98 \\
\hline $\mathrm{S} 2$ & 41 & 28 & 333 & 2.44 & $2.02-2.85$ & 0.85 & 7.99 & $7.68-8.30$ & 0.99 \\
\hline $\mathrm{S} 3$ & 36 & 15 & 105 & 0.98 & $0.74-1.22$ & 0.84 & 2.59 & $2.23-2.94$ & 0.93 \\
\hline S4 & 34 & 9 & 34 & 0.46 & $0.41-0.51$ & 0.99 & 0.73 & $0.45-1.00$ & 0.84 \\
\hline S5 & 18 & 5 & 177 & 1.89 & $1.72-2.06$ & 0.97 & 8.44 & $7.89-9.00$ & 0.98 \\
\hline
\end{tabular}

Where $N I_{j, s}$ is the mean abundance of species $s$ across the stations relating to stratum $J ; N I_{+j}$ is the sum of the mean abundances of species $s$ in the various depth strata; $N S_{j, s}$ is the number of stations in $J$ where the species $s$ is present; $N I_{j+}$ is the total number of stations in that depth stratum.

The specificity value $\left(S P_{j, s}\right)$ is maximum when the species $s$ is present in depth stratum $J$ only, whereas the fidelity value $\left(F I_{j, s}\right)$ is maximum when the species $s$ is present at all stations of $J$.

The specificity and fidelity represent information independently from one another, their product multiplied by 100 produces the indicator value $I V_{j, s}$ (Dufrêne and Legendre, 1997):

$$
I V_{j, s}=100 S P_{j, s} F I_{j, s}
$$

This index, varying from 0 to 100 was used to identify the indicator species for each depth stratum.

\section{Results}

\subsection{Point diversity and density: probability distributions}

The fits of the Poisson density function to the number of species per haul per stratum were very good (Table 1; Fig. 2 ). Along the depth gradient, there was a consistent trend of declining $\lambda$ (point diversity) from S1 to $\mathrm{S} 4$ followed by an increase in S5. The confidence intervals of $\lambda$ clearly show that the changes with depth are statistically significant. The fit to all the stations was slightly poorer than in any individual stratum except for S3. In other words, the point diversity followed better a Poisson's probability distribution when depth was approximately constant.

The fits of the exponential distribution to the number of individuals per station in a stratum were also good. The cumulative distributions were in agreement with the observations (Table 1; Fig. 3 ), and $R^{2}$ values were high except in the strata $\mathrm{S} 1$ and S5. The $R^{2}$ for the entire data set was higher than the average of the strata. The mean $\mu$, showed the same pattern of variation with depth as $\lambda$. The changes from one stratum to another were statistically significant except between $\mathrm{S} 1$ and $\mathrm{S} 2$.

\subsection{Alpha diversity}

$N_{0}$, decreased from 53 in $\mathrm{S} 1$ to 5 in S5; also $N_{1}$ decreased but at a lower rate (Table 2). Based on $N_{2}$, the diversity in $\mathrm{S} 1$ appeared to be lower than in S2 indicating a stronger

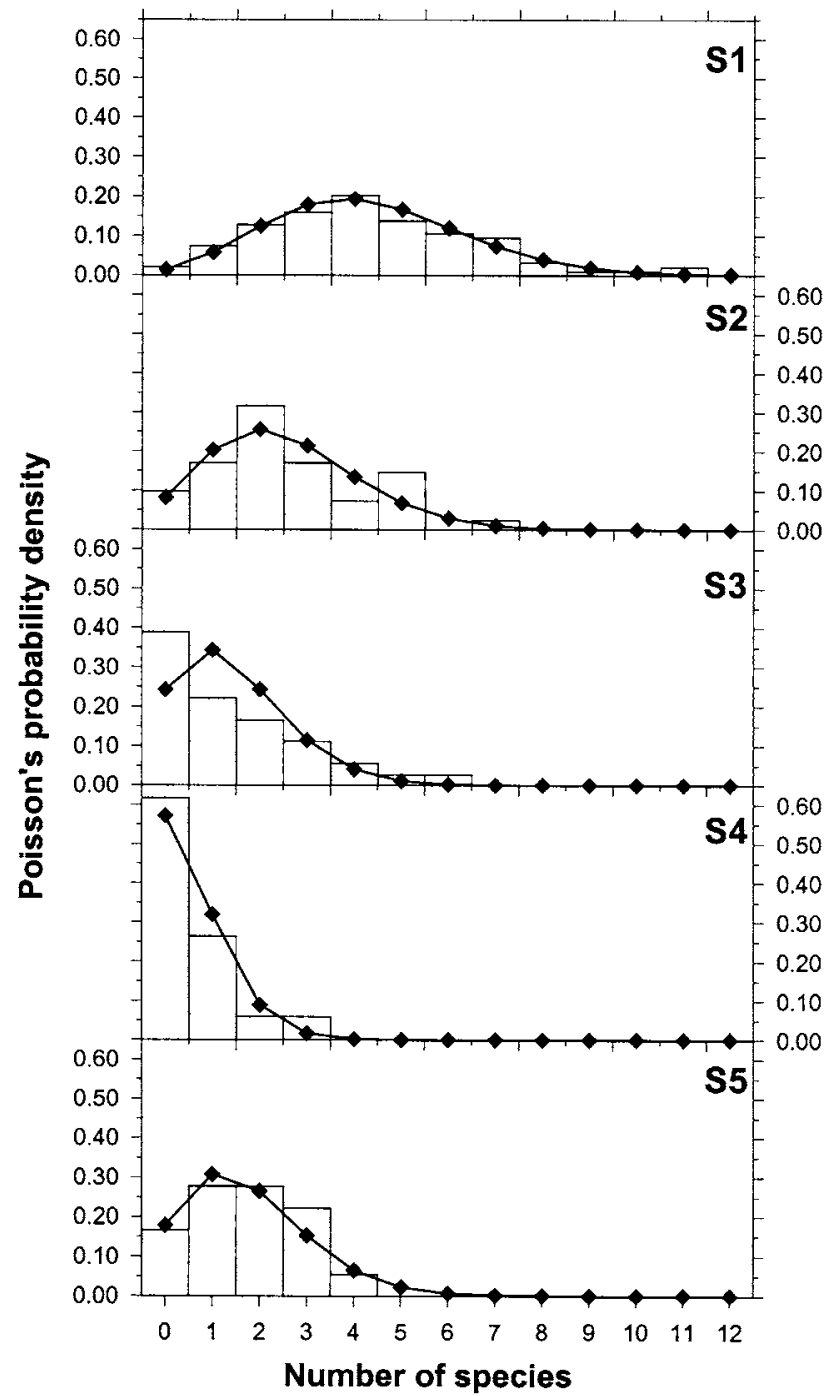

Fig. 2. Histograms of observed distribution of the number of species per station, and their fitting curve (continuous line and symbols) to the Poisson's probability distribution in the 5 depth strata, S1: 22-224 m; S2: 278-437 m; S3: 495-594 m; S4: 656-777 m and S5: 816-1208 m. 


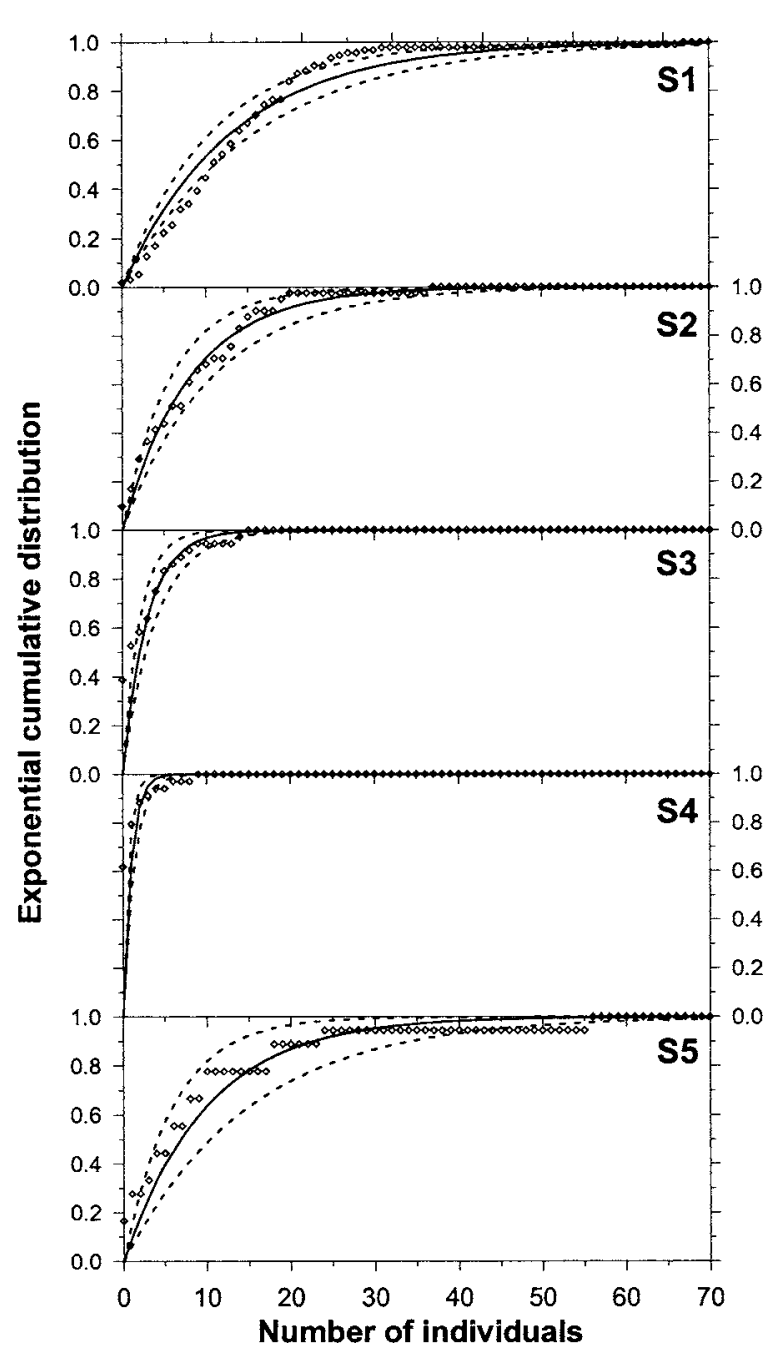

Fig. 3. Observed cumulated distribution of the number of individuals per station (diamonds), and their fitting curve (continuous line) to the cumulated exponential probability function in the 5 depth strata.

dominance structure in S1. The last index of the Hill's series $\left(N_{\infty}\right)$ reflected the high dominance of the most common species in S1 and S5 (respectively Pagrus pagrus and Mora moro).

Evenness increased from S1 to S4, then decreased in S5 (Table 2). The evenness in S1a and S1b were respectively, lower and higher than in S1. Evenness was higher in S1b than in S1a. For the whole area, its value was close to that in S1 and lower than in S2-S5.
Table 3

Beta diversity: within habitat $\left(\beta_{\mathrm{S}}\right)$ and turnover $\left(\beta_{\mathrm{D}}\right)$ between adjacent strata

\begin{tabular}{lll}
\hline Stratum & $\beta_{\mathrm{S}}$ & $\beta_{\mathrm{D}}$ \\
\hline S1 & 12.44 & $(\mathrm{~S} 1-\mathrm{S} 2) 0.60$ \\
S1a & 9.77 & 0.45 \\
S1b & 7.20 & 0.49 \\
S2 & 11.48 & 0.35 \\
S3 & 15.31 & 0.58 \\
S4 & 19.57 & 0.71 \\
S5 & 2.65 & \\
\hline
\end{tabular}

The $\Delta$ index behaved intermediately between $N_{1}$ and $N_{2}$ (Table 2) indicating a stable diversity from S1 to $\mathrm{S} 4$ then a drop in S5. The pure taxonomic distinctness index $\Delta^{*}$ was quite stable over the 5 strata.

\subsection{Beta diversity}

$\beta_{\mathrm{S}}$ was the lowest in S5, meaning that in this stratum the total species richness can be observed from a few sampling units (stations). $\beta_{\mathrm{S}}$ was intermediate in $\mathrm{S} 1$ and $\mathrm{S} 2$ and high in $\mathrm{S} 3$ and $\mathrm{S} 4$. In the sub-strata $\mathrm{S} 1 \mathrm{a}$ and $\mathrm{S} 1 \mathrm{~b}, \beta_{\mathrm{S}}$ was lower than in S1 (Table 3).

$\beta_{\mathrm{D}}$, in other words the replacement of species, was the smallest between S2 and S3 (Table 3). The change from S1a to $\mathrm{S} 1 \mathrm{~b}$ was similar to that between $\mathrm{S} 1$ and $\mathrm{S} 2$ (shelf break). The similarity of S2 and S3 indicates that these strata were little different in terms of species composition although the point diversity and the density were significantly lower in $\mathrm{S} 3$ than in S2. Beyond the shelf break, the change increased with depth and was the highest between S4 and S5 (4 of the 5 species caught in S5 were not caught shallower).

\subsection{Indicator species}

There were few indicator species. Four species were indicators of S1, 2 of S2 and 3 of S5. The intermediate strata S3 and S4 had no indicator species (Fig. 4). Indicator species of S1 were all specific to this stratum (Specific-

Table 2

Hill's diversity indices of order $0,1,2$ and $+\infty$, taxonomic distinctness indices ( $\Delta$ and $\Delta^{*}$ ) and evenness indices per strata and in the sub-strata of S1 (see text)

\begin{tabular}{llrllllll}
\hline Stratum & $N_{0}$ & $N_{1}$ & $N_{2}$ & $N_{\infty}$ & $\Delta$ & $\Delta^{*}$ & $E_{(1,0)}$ & $E_{(2,1)}$ \\
\hline All & 73 & 21.5 & 10.7 & 3.9 & 3.0 & 3.4 & 0.29 & 0.50 \\
S1 & 53 & 13.7 & 5.7 & 2.6 & 2.6 & 3.2 & 0.25 & 0.41 \\
S1a & 38 & 8.0 & 3.5 & 1.9 & 2.3 & 3.2 & 0.21 & 0.43 \\
S1b & 35 & 14.6 & 8.6 & 3.9 & 2.8 & 3.2 & 0.42 & 0.58 \\
S2 & 28 & 10.3 & 6.5 & 3.7 & 3.0 & 3.5 & 0.37 & 0.63 \\
S3 & 15 & 8.5 & 6.1 & 3.3 & 2.8 & 3.3 & 0.57 & 0.72 \\
S4 & 9 & 6.4 & 5.3 & 3.4 & 2.7 & 3.2 & 0.71 & 0.83 \\
S5 & 5 & 1.8 & 1.4 & 1.2 & 0.9 & 3.4 & 0.36 & 0.75 \\
\hline
\end{tabular}




\section{Indicator species}
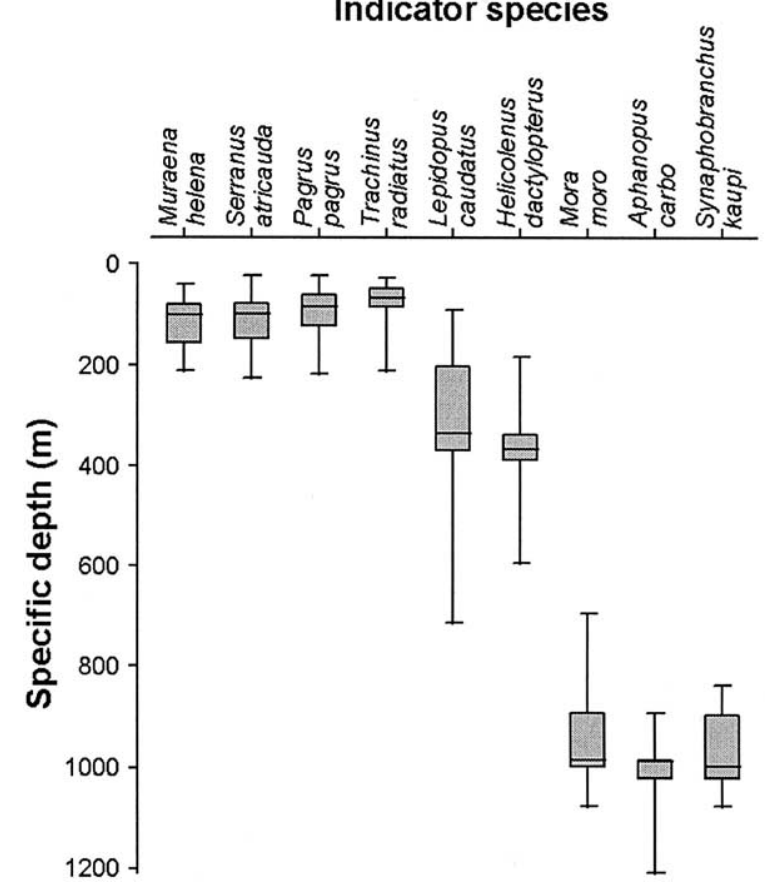

Fig. 4. Box and whiskers plot of the distribution of the weighted depth of occurrence of each indicator species. The upper and lower ends of the central box indicate the 75 th and 25 th percentiles of the data, the central line indicates the median. The whiskers are lines extending from each end of the box to show the extent of the rest of the data.

ity $=1$ ) and had indicator values ranging from 81 for Pagrus pagrus to 21 for Muraena helena. The two indicator species of stratum S2 had an extended depth range (Fig. 4) and moderate fidelities resulting in quite low indicator values (44 for Helicolenus dactylopterus, 20 for Lepidopus caudatus). Indicator species of S5 were almost completely restricted to S5 (specificity equal or very close to 1 ). However, with the exception of Mora moro $(I V=72)$, they had low indicator values (44 for Synaphobranchus kaupi, 39 for Aphanopus carbo) due to low fidelities.

\section{Discussion}

\subsection{Depth distribution and diversity of carnivorous fish around Lanzarote and Fuerteventura}

The size of the fishing gear used to sample the stations was small enough to: (i) consider that it clearly was a sample of point diversity and (ii) produced the necessary data and the required conditions for the application of the Poisson distribution (see e.g., Elliott, 1977).

Although, Mora moro was considered as aggregated on its spawning ground (Uiblein et al., 1996, 1998) in S5, this aggregative character should be regarded as a scale question. Indeed, the number of fish caught per longline was still relatively low.

All Hill's indices were low in S5. This is caused by a low number of species (low $N_{0}$ and $N_{1}$ ) and a high dominance structure (low $\mathrm{N}_{2}$ ). The two evenness indices tracked each other quite well suggesting that the sensitivity of $E_{1,0}$ to the species richness was not too strong in our case. In previous studies, $\Delta$ and $\Delta^{*}$ were successfully used for benthic invertebrates (Warwick and Clarke, 1995). However, when used for fish diversity they did not add extra information with respect to Hill's indices (Hall and Greenstreet, 1998). This could have been a consequence of the narrowness of the taxon 'fish' or of the special case studied. Here $\Delta$ suggested the same trend as Hill's indices but $\Delta^{*}$ was very similar in S5 (with only five species) and S1-S4. Considering that the taxonomic diversity reflects a diversity of ecological niches and functions (Frontier and Leprêtre, 1998; Wiens, 1989), this high taxonomic distinctness realised with few species may suggest that, in S5, the functional diversity of carnivorous fish is kept despite of a low number of species due to oligotrophic conditions. As a consequence, in this S5 stratum, there would be a low functional species redundancy, implying a sensitivity of this deep-water assemblage to disturbance. Nevertheless, it should also be stressed that S5 does not include all the areas around the Islands as did the other strata, but was restricted to a small area. This stratum has both a very low species richness and a strongly dominant species. It may represent a restricted homogeneous habitat, while shallower strata may be more habitat heterogeneous (so that a part of what was ascribed here to the alpha diversity could be beta diversity).

Beta diversity is most often dealt with in terms of species richness and comparison of species composition. Estimates of beta diversity may then be sensitive to sample size. Here, alpha diversity was estimated from several Hill's indices and the relationships between point, alpha and beta diversity were investigated in terms of species richness.

As $\beta_{\mathrm{S}}$ is sensitive to the sample size, it is worth noting that lower values were observed in the two most intensively sampled strata (S1, S2) and higher values in strata with smaller sample size (S3, S4). As the sample size plays the around way round ( $\beta_{\mathrm{S}}$ increases with sample size), this is not an artefact. However, the scatter plot of $N_{0}$ vs. $\lambda$ (Fig. 5) rather suggests a common relationship between the two from $\mathrm{S} 1$ to $\mathrm{S} 4$. The smaller $\beta_{\mathrm{S}}$ in $\mathrm{S} 1 \mathrm{a}, \mathrm{S} 1 \mathrm{~b}$ and especially S5 also appears graphically. The comparisons between the point diversity and the alpha diversities of different orders make a complementary approach to the beta $\left(\beta_{\mathrm{S}}\right)$ diversity. Over the full range of Hill's indices, the alpha diversity in S5 is low compared with $\lambda$. In the other strata, the relationship between point and alpha diversity is similar when this latter is defined in terms of $N_{0}$ and $N_{1}$, it weakens for $N_{2}$ and may invert for $N_{\infty}$ (Fig. 5).

\subsection{Relationships with other approaches}

The indicator species can be regarded as major contributors to the beta diversity. For example, the low $\beta_{\mathrm{S}}$ in S5 is related to the fidelities of 3 of the 5 species caught in this 


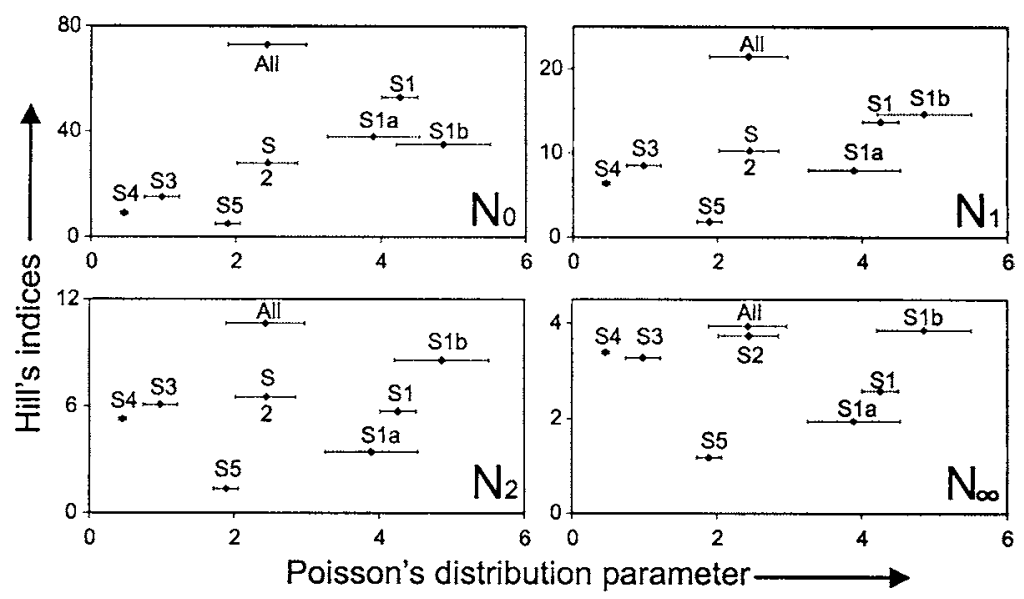

Fig. 5. Relationship between the point species richness as estimated from the parameter of the Poisson's distribution $(\lambda$ : $x$-axis) and Hill's indices of the alpha diversity per stratum. stratum. On the other hand, the same 3 species should represent most of the high $\beta_{\mathrm{D}}$ between S4 and S5. Fidelities and specificities can be regarded as the species-specific counterpart of the beta diversity.

Another representation of the beta diversity along the depth gradient is a curve of the cumulative number of species observed with increasing depth (Fig. 6). This shows a major change at the shelf break where no new species appear over a wide depth range. At the same depth many species had their last occurrence suggesting that it is a depth range where shelf species extend toward the slope but there is no typical fish fauna there. Then, several new species are found at the start of S2 implying a high value of $\beta_{\mathrm{D}}$ between $\mathrm{S} 2$ and shallower strata (S1 or the substrata S1b). Deeper, $\mathrm{S} 3$ brings almost no new species but some disappear. In S4 and to a lesser extend in S5, there is a visible break both in terms of first and last occurrence. All this is consistent with the $\beta_{\mathrm{D}}$ series.

\subsection{Availability of longlining data, selectivity and potential use of the proposed approach}

The species richness observed from longline sampling is lower than that obtained from trawl sampling (Connolly and Kelly, 1996; Hareide, 1995; Reinert, 1995). This is probably the main reason why longline data are rarely used for ecological purposes. Along the slope, the species caught are large predators such as chondrichthyans and several large gadiform, scorpaeniform and trichiurid species. The abundant deep-sea scavenger, Synaphobranchus kaupi, is also caught while the large predator Hoplostethus atlanticus and the abundant North Atlantic Coryphaenoides rupestris hardly take any bait. However, any kind of trawl is selective too. At slope depth, it was shown that analyses relying on one single gear could provide little ecologically relevant information (Gordon, 1986; Gordon and Bergstad, 1992; Gordon et al., 1996; Merrett et al., 1991). Nevertheless, we believe that in areas where only longlines can be operated, this restricted data should be used. Where exploitation relies primarily upon longlining, behaviourally dominant predators (Godø et al., 1997), and the largest individuals (Engås et al., 1996; Hareide, 1995; Løkkeborg and Bjordal, 1992; Reinert, 1995), better competing for bait, should undergo a higher fishing mortality. Species caught on longlines are often the most long-lived in a given ecosystem and they also often represent the most valuable fishery-exploited species. The combination of the two characters make these species highly sensitive to exploitation in particular in the case of the deep waters and hence more attention should be paid to this valuable but most vulnerable component of the fish assemblage.

In addition to comparison of depth strata, the same method could apply to spatial differences and be expanded to investigations of changes over time. The latter application may become of major interest in the context of marine protected areas (MPAs). For example, if MPAs were set to protect seabeds from human impact, the use of trawling for sampling would not be desirable. Submersibles and remote operation vehicles (ROVs) are then likely to become the major tools for field studies. However, ROVs are unlikely to become easily available except for large research programs,

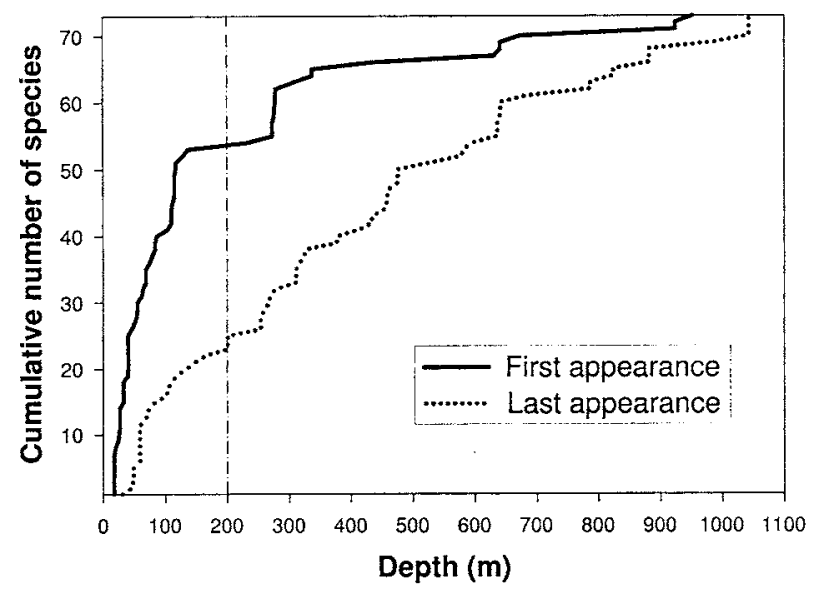

Fig. 6. Cumulative number of species observed along the studied depth gradient. 
while MPAs may be implemented at local scale for conservation purposes.

Due to overexploitation of numerous shelf resources, the development of fisheries in deeper waters is likely to continue. Time series of longlining surveys in areas such as the Canaries should be useful to monitor such developments. The account of the different components of the diversity should also be generalised as our study highlights that statements such as "diversity peaks at depth of..." can be very misleading. The total diversity of the studied area is a further component (gamma) of the diversity. It was not dealt upon in this paper as it is of little interest when dealing with one single area. In the case at hand, the diversity structure can be summarised as follows. The small scale (point) diversity and the fish density decrease with depth down to $800 \mathrm{~m}$ and increases in the deeper strata. The habitat (alpha) diversity decreases along the entire depth gradient but the taxonomic distinctness remains the same. At the same time, the within habitat $\left(\beta_{\mathrm{S}}\right)$ diversity increases down to $800 \mathrm{~m}$ and then decreases. The turnover diversity $\left(\beta_{\mathrm{D}}\right)$ suggests two major faunal breaks at the shelf break and at about $800 \mathrm{~m}$. Both the shallowest and deepest strata had low evenness (at least in term of the most usual index, $E_{1,0}$. This is also reflected by the presence of several indicator species in these strata. Thus the carnivorous fish fauna can be understood as comprised of 3 major assemblages: shelf, upper slope and mid-slope that are different both in terms of species composition and point, alpha and beta diversities.

\section{Acknowledgements}

We would like to thank Drs. Kristin Helle and Michael Pennington for valuable comments and suggestions. The present study was carried out with financial support of the scientific department of the French Embassy at Vienna, the Austria academic exchange service (ÖAD), and a bilateral Amadeus project, Project nr.V.13. It is also a contribution to ELICO 'Ecosystèmes Littoraux Côtiers', to PNEC 'Programme National d'Environnement Côtier' program of CNRS and the contribution $\mathrm{N}^{\circ} 5$ of the Ecosystem Complexity Research Group.

\section{References}

Connolly, P.L., Kelly, C.J., 1996. Catch and discards from experimental trawl and longline fishing in the deep-water of the Rockall Trough. J. Fish Biol. 49 (Suppl. A), 132-144.

Dufrêne, M., Legendre, P., 1997. Species assemblages and indicator species: the need for a flexible asymmetrical approach. Ecol. Monogr. 67, 345-366.

Elliott, J.M., 1977. Some methods for the statistical analysis of Benthic Invertebrates, vol. 25, Freshwater Biological Association. Scientific publication, Ambleside, UK.

Engås, A., Løkkeborg, S., 1994. Abundance estimation using bottom gillnet and longline - the role of fish behaviour. In: Fernö, A., Olsen, S. (Eds.),
Marine Fish Behaviour in Capture and Abundance Estimation. Fishing News Books, London, pp. 134-165.

Engås, A., Løkkeborg, S., Soldal, A.V., Ona, E., 1996. Comparative fishing trials for cod and haddock using commercial trawl and longline at two different stock levels. Gear Selectivity Technical Interactions in Mixed Species Fisheries Symposium. Dartmouth N.S, pp. 83-90.

Frontier, S., Leprêtre, A., 1998. Développements récents en théorie des écosystèmes. Ann. Inst. Oceanogr. 74, 43-87.

Godø, O.R., Huse, I., Michalsen, K., 1997. Bait defence behaviour of wolffish and its impact on longline catch rates. ICES J. Mar. Sci. 54, 273-275.

Gordon, J.D.M., 1986. The fish populations of the Rockall Trough. Proc. R. Soc. Edinb. 88B, 191-204.

Gordon, J.D.M., Bergstad, O.A., 1992. Species composition of demersal fish in the Rockall Trough, northeastern Atlantic, as determined by different trawls. J. Mar. Biol. Assoc. UK 72, 213-230.

Gordon, J.D.M., Merrett, N.R., Bergstad, O.A., Swan, S.C., 1996. A comparison of the deep-water demersal fish assemblages of the Rockall Trough and Porcupine Seabight, eastern north Atlantic: continental slope to rise. J. Fish Biol. 49 (Suppl. A), 217-238.

Gray, J.S., 2000. The measurement of marine species diversity, with an application to the benthic fauna of the Norwegian continental shelf. J. Exp. Mar. Biol. Ecol. 250, 23-49.

Hall, S.J., Greenstreet, S.P., 1998. Taxonomic distinctness and diversity measures: responses in marine fish communities. Mar. Ecol. Prog. Ser. $166,227-229$.

Hareide, N.-R., 1995. Comparisons between longlining and trawling for deep-water species - selectivity, quality and catchability - a review. In: Hopper, A.G. (Ed.), Deep-water Fisheries of the North Atlantic Oceanic Slope. Kluwer Academic Publishers, Dordrecht, pp. 227-234.

Hill, M.O., 1973. Diversity and evenness: a unifying notation and its consequences. Ecology 54, 427-432.

Hovgard, H., Riget, F.F., 1992. Comparison of longline and trawl selectivity in cod surveys off west Greenland. Fish. Res. 13, 323-333.

Iglesias, S., Paz, J., 1995. Spanish north Atlantic deep-water fisheries. In: Hopper, A.G. (Ed.), Deep-water Fisheries of the North Atlantic Oceanic Slope. Kluwer Academic Publishers, Dordrecht, pp. 287-295.

Leite, A.M., 1988. The deep-sea fishery of the black scabbard fish Aphanopus carbo Lowe, 1839 in Madeira Island waters. World Symposium on Fishing Gear and Fishing Vessel Design, 20 November 1988. St. John's, NF Canada, pp. 240-243.

Løkkeborg, S., 1994. Fish behaviour and longlining. In: Fernö, A., Olsen, S. (Eds.), Marine Fish Behaviour in Capture and Abundance Estimation. Fishing News Books, London, pp. 9-27.

Løkkeborg, S., Bjordal, A., 1992. Species and size selectivity in longline fishing: a review. Fish. Res. 13, 311-322.

Lorance, P., Souissi, S., Uiblein, F., Castillo Eguia, R., 2001. Distribution and density of carnivorous fish species around Lanzarote and Fuerteventura, Canary Islands. NAFO Scientific Council Meeting, NAFO SCR Doc. 01/168. Varadero, Cuba, pp. 14.

Martins, R., Ferreira, C., 1995. Line fishing for black scabbard fish (Aphanopus carbo Lowe, 1839) and other deep-water species in the eastern mid Atlantic to the north of Madeira. In: Hopper, A.G. (Ed.), Deep-water Fisheries of the North Atlantic Oceanic Slope. Kluwer Academic Publishers, Dordrecht, pp. 323-335.

Merrett, N.R., Gordon, J.D.M., Stehmann, M., Haedrich, R.L., 1991. Deep demersal fish assemblage structure in the Porcupine Seabight (eastern north Atlantic): slope sampling by three different trawls compared. J. Mar. Biol. Assoc. UK 71, 329-358.

Piñeiro, C.G., Casas, M., Bañon, R., 2001. The deep-water fisheries exploited by Spanish fleets in the Northeast Atlantic: a review of the current status. Fish. Res. 51, 311-320. 
Reinert, J., 1995. Deep-water resources in Faroese waters to the south, southwest and west of the Faroes - a preliminary account. In: Hopper, A.G. (Ed.), Deep-water Fisheries of the North Atlantic Oceanic Slope. Kluwer Academic Publishers, Dordrecht, pp. 201-225.

Rico, V., Santana, J.I., Gonzalez, J.A., 1999. Técnicas de pesca artesanal en la isla de Gran Canaria Gobierno de Canarias, Instituto Canario de Ciencas Marinas Las Palmas, Gran Canaria Calbildo de Gran Canaria, Area de Educación.

Uiblein, F., Bordes, F., Castillo, R., 1996. Diversity, abundance and depth distribution of demersal deep-water fishes off Lanzarote and Fuerteventure, Canary Islands. J. Fish Biol. 49, 75-90.
Uiblein, F., Bordes, F., Castillo, R., Ramos, A.G., 1998. Spatial distribution of shelf- and slope-dwelling fishes collected by bottom longline off Lanzarote and Fuerteventura, Canary Islands. Mar. Ecol. 19, 53-66.

Warwick, R.M., Clarke, K.R., 1995. New biodiversity measures reveal a decrease in taxonomic distinctness with increasing stress. Mar. Ecol. Prog. Ser. 129, 301-305.

Whittaker, R.H., 1960. Vegetation of the Siskiyou Mountains. Oregon and California. Ecol. Monogr. 30, 279-338.

Wiens, J.A., 1989. Spatial scaling in ecology. Funct. Ecol. 3, 385-397. 